\title{
Design Guidelines for a Virtual Coach for Post-Traumatic Stress Disorder Patients
}

\author{
Myrthe Tielman ${ }^{1}$, Willem-Paul Brinkman ${ }^{1}$, and Mark A. Neerincx ${ }^{1,2}$ \\ 1 Delft University of Technology, Delft, The Netherlands \\ 2 TNO Human Factors, Utrecht, The Netherlands
}

\begin{abstract}
Patients with Post Traumatic Stress Disorder (PTSD) often need to specify and relive their traumatic memories in therapy to relieve their disorder, which can be a very painful process. One new development is an internet-based guided self-therapy system (IBGST), where people work at home and a therapist is remotely involved. We propose to enrich an IBGST with a virtual coach to motivate and assist the patient during the therapy. We have created scenarios and requirements for an IBGST coach and discussed these with 10 experts in structured interviews. From these interviews, we have identified 10 important guidelines to assist with the design of a virtual coach assisting with PTSD treatment.
\end{abstract}

Keywords: Virtual coach, PTSS, Guidelines, Structured interviews.

\section{Introduction}

An important upcoming role for virtual agents is coaching, the task of motivating and assisting people to achieve their goals. Blanson-Henkemans et al. 11 show that a virtual coach can motivate and support people successfully. Rizzo et al. 2] present a virtual coach which can be used to assist Post-Traumatic Stress Disorder (PTSD) patients by guiding them towards information.

PTSD is a mental disorder following one or more traumatic experiences with symptoms such as intrusive memories of the traumatic event, dissociative reactions and irritable behavior [3]. One of the most practiced treatments for PTSD is Cognitive Behavioral Therapy (CBT) with exposure, which is the process of exposing the patient to stimuli which are related to the traumatic memory and will elicit a fear response.

A new development within the treatment of PTSD is an internet-based guided self-therapy (IBGST) system, where people work at home and a therapist is only remotely involved. In this paper we will focus on the Multi-Model Memory Restructuring (3MR) system [4, which allows patients to structure memories and follow exposure-therapy on their own PC through creating memories on a visual timeline and adding media such as photos, music and text. An additional functionality is the possibility to recreate personal memories in a $3 \mathrm{D}$ environment. One difficulty is that exposure treatments can be very painful and possibly demotivating at times. For this reason, we believe that a virtual coach would be a very useful addition to the system. Such a coach could be capable of offering 
Table 1. Guidelines for a virtual coach for PTSD

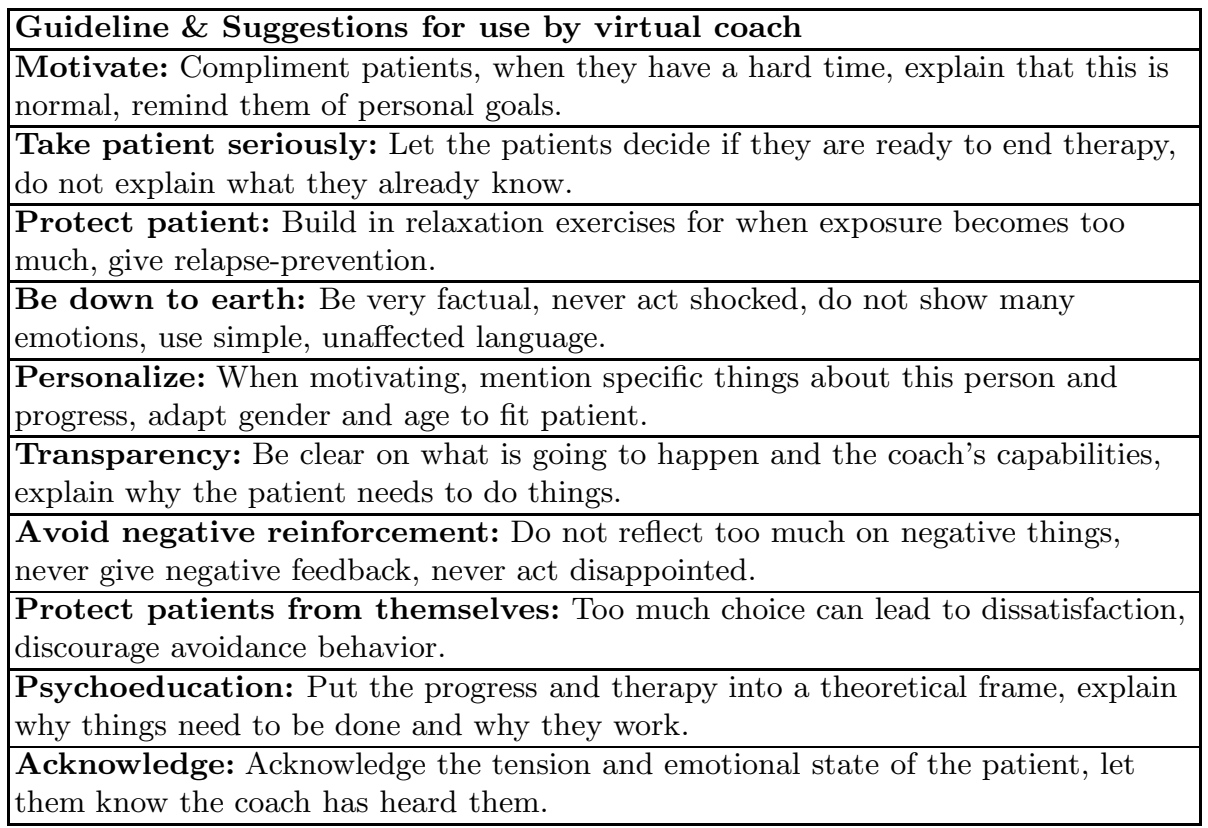

Table 2. A decomposition of the guideline of Motivation for a virtual coach for PTSD

\begin{tabular}{|l|l|}
\hline Motivational theme & Explanation for use by virtual coach \\
\hline Compliment & Give concrete, but many compliments \\
\hline Empathy & Show empathy, but never include strong feelings \\
\hline Evaluate & Set concrete goals to evaluate progress and outcome \\
\hline Doing badly is not possible & There is no 'wrong' way to do things \\
\hline Personalize & Motivate in a personalized way, be as concrete as possible \\
\hline Be positive & Give positive feedback and reflect most on positive things \\
\hline
\end{tabular}

personalized and motivational assistance during the therapy process, increasing trust in the therapy and hope in a positive outcome.

In this paper, we present the first steps towards developing such a virtual coach for patients with PTSD working with the IBGST 3MR system. Because of differences between PTSD patients we have chosen to focus on two specific patient groups, namely victims of childhood sexual abuse (CSA) and military veterans.

\section{Structured Interviews}

To determine the specific user requirements for PTSD patients, we have designed scenarios with discussed these in structured interviews with 10 experts. 
We adopted a scenario-based approach to inform the experts on the context in which our coach would be operating. The scenarios represented the types of sessions a patient would follow during treatment including a possible way in which the virtual coach could assist and also described aspects of behavior of the virtual coach which were based on literature on motivation 5 and medical communication guidelines [6]. From the scenarios we identified requirements for the coach, dealing with topics such as facial expressions, giving explanations on the therapy and motivation. From these requirements we formulated strong claims such as 'It would pose a problem if the virtual coach had the same characteristics with each patient' to stimulate a discussion. In structured interviews, we presented the scenarios and claims to 10 experts specialized in trauma treatment. The interviews were conducted in 6 sessions, each with 1 to 3 experts present. Each session discussed between 6 and 24 claims.

All interviews were recorded and the statements of the experts were written down. After this, we determined the underlying guideline and grouped the statements. From this analysis, we derived the guidelines as shown in Table 1. From the contexts, we can also present some suggestions for the use of each guideline. Motivating a patient was mentioned often, so we also considered what the experts said on motivation in more detail and identified six ways of motivating, as shown in Table 2.

\section{Discussion and Conclusion}

A first observation we can make of our guidelines is that they agree with the principles identified by Miller and Rollnick and Wouda at al. [5]6]. Another thing to consider is the role of our virtual coach. Based on the guidelines identified we can say that the coach can be a safe-guard, an educator and a motivator. These three roles correspond to roles a human therapist would also have, but a virtual coach does have its own limitations and possibilities which set it apart. Opportunities for a virtual coach may lie with being down to earth and personalization. A virtual coach will never have strong emotional reactions to traumatic memories which would need to be kept in check and a virtual coach has the unique quality that appearance, age and gender can be adapted specifically for a patient. Another difference which is connected to personalization is the support of memory retrieval. Therapists typically ask questions to assist patients with remembering, and it is important that these questions are well tailored to the patient. For humans natural language is the key ingredient, which is challenging for a virtual coach. However, because the coach is embedded into a system it has more modalities available. A coach could react to items which are placed in the application, for instance ask who is present in a photograph or a video. Another example is that a coach could notice how many items are added when specific questions are asked to keep track of which questions work well for which patient.

To conclude this paper, we would like to give examples of some of the ways in which our guidelines could be applied to specific functions and behavior of a virtual coach. These are presented in Table 3. 
Table 3. Examples of behavior for a virtual coach for PTSD, based on the guidelines

\begin{tabular}{|l|l|}
\hline Potential behavior of a virtual coach coach & Guideline \\
\hline $\begin{array}{l}\text { When patients fill in how they feel, mention that you have heard } \\
\text { them, i.e. 'I notice you are feeling distressed now.' }\end{array}$ & Acknowledge \\
\hline In the beginning of a session, explain what is going to happen. & Transparency \\
\hline If the patient indicates wishing to quit, remind them of their goals. & Motivate \\
\hline Let the patient choose the gender of their coach. & Personalization \\
\hline $\begin{array}{l}\text { Be factual in complementing, so do not say 'Great job, amazing, } \\
\text { you are wonderful', but 'You completed this task, well done'. }\end{array}$ & $\begin{array}{l}\text { Be down to } \\
\text { earth }\end{array}$ \\
\hline $\begin{array}{l}\text { Never express a negative emotion. Whenever the patient fails to do } \\
\text { something, do not punish but ask them why they did not do it. }\end{array}$ & $\begin{array}{l}\text { the negative } \\
\text { If distress is very high, explain that this is normal and will decrease. }\end{array}$ \\
\hline Msychoeducation \\
\hline $\begin{array}{l}\text { Whenitor symptoms, if these keep increasing, notify a therapist. } \\
\text { explicitly. 'I know you have heard this before, but...' }\end{array}$ & Protect patient \\
\hline $\begin{array}{l}\text { Do not let patients decide when to start with exposure by } \\
\text { themselves, assist them in setting a date. }\end{array}$ & $\begin{array}{l}\text { Take patient } \\
\text { seriously }\end{array}$ \\
\hline
\end{tabular}

Acknowledgements. This work is part of the research programme VESP, which is supported by the Netherlands Organization for Scientific Research (NWO), program Creative Industry (project number 314-99-104).

\section{References}

1. Blanson-Henkemans, O.A., van der Mast, C.A., van der Boog, P.J., Neerincx, M.A., Lindenberg, J., Zwetsloot-Schonk, B.J.: An online lifestyle diary with a persuasive computer assistant providing feedback on self-management. Technology and Health Care 17, 253-267 (2009)

2. Rizzo, A., Lange, B., Buckwalter, J.G., Forbell, E., Kim, J., Sagae, K., Williams, J., Difede, J., Rothbaum, B.O., Reger, G., Parsons, T., Kenny, P.: Simcoach: an intelligent virtual human system for providing healthcare information and support. In: Proc. 8th Intl Conf. Disability, Virtual Reality \& Associated Technologies (2010)

3. American Psychiatric Association: Diagnostic and Statistical Manual of Nental Disorders, 5th edn. American Psychiatric Association (2013)

4. Brinkman, W.P., Vermetten, E., van den Steen, M., Neerincx, M.: Cognitive engineering of a military multi-modal memory restructuring system. Journal of CyberTherapy and Rehabilitation 4(1), 83-99 (2011)

5. Miller, W.R., Rollnick, S.: Motivational interviewing: Preparing people to change addictive behavior. Guilford Press, New York (1991)

6. Wouda, J., van de Wiel, H., van Vliet, K.: Medische communicatie, Gespreksvaardigheden voor de arts. De Tijdstroom (2000) 